\title{
Designing a time-effective TaqMan probe-based real-time polymerase chain reaction protocol for the identification of Yersinia enterocolitica in raw pork meat
}

\author{
Milena Alicja Stachelska \\ Lomza State University of Applied Sciences, Institute of Food Technology and Gastronomy, \\ Łomża, Poland \\ Received March 10, 2017 \\ Accepted December 19, 2017
}

\begin{abstract}
The aim of this study was to design a time-effective method comprising a short pre-enrichment step in a non-selective broth in combination with the TaqMan probe applied in the real-time polymerase chain reaction to detect Yersinia enterocolitica strains in raw pork meat. The method enabled to detect 1 colony forming unit per $25 \mathrm{mg}$ of Yersinia enterocolitica in pork meat. The specificity and reliability of the method was not diminished by the company of microflora naturally present in meat. The method was found successful to detect pathogenic Yersinia enterocolitica strains in pork meat. It is advised to be used for assessing the microbial risk and for controlling the microbial quality of meat and meat products.
\end{abstract}

Pathogenicity, molecular biology, enrichment, detection

Meat and meat products possess very high nutritional value and are rich with compounds required for the growth of naturally present microflora. Meat is quite often contaminated with different pathogenic microorganisms. Such phenomenon imposes the necessity to guarantee the safety of meat and meat products in order to eliminate the risk of exposing the consumer to food-borne diseases caused by the consumption of contaminated foodstuffs. The development of successful analytical methods to detect the presence of pathogens in meat and meat products becomes crucial (Kocher et al. 1989; Herman 2001; Heptinstall and Rapley 2002). Such detection methods enable to confirm or exclude the presence of pathogenic bacteria in meat and meat products with reliable results (Koppel et al. 2011). They could be used for food hygiene purposes and may also predict the potential risk of the presence of pathogenic strains. Classical culture-based detection methods sometimes do not deliver accurate and reliable results; moreover, they are tedious and time-consuming. They do not find their application because they do not meet the requirements of the meat industry which produces on a massive scale, when the safety of large amounts of meat and meat samples must be determined relatively fast (Girish et al. 2007; Kesmen et al. 2007).

Nowadays, molecular methods based on the sequencing of nucleic acids involving the polymerase chain reaction (PCR) and the real-time polymerase chain reaction (real-time PCR) are used as they are reliable, specific, sensitive and time saving protocols for both qualitative and quantitative detection of various pathogenic microorganisms in meat and meat products (Tanabe et al. 2007; Jonker et al. 2008). Special attention should be paid to the real-time PCR method which is gaining popularity in different analytical applications in food processing, making it possible to detect various pathogenic bacteria and monitor the gene expression of bacteria caused by industrial procedures (Dooley et al. 2004). Real-time PCR is the molecular method which enables the simultaneous amplification and detection of specific deoxyribonucleic acid (DNA) sequences. The analysis is carried out in a thermocycler. This method is rapid, specific, sensitive and reliable. It is less risky in terms of carryover contamination in comparison to the conventional PCR method (Walker

Address for correspondence:

Milena Alicja Stachelska

Institute of Food Technology and Gastronomy

Lomza State University of Applied Sciences

Phone: +48 798385983

Akademicka 14, 18-400 Łomża, Poland 
et al. 2003; Mane et al. 2009). A large number of chemistries have been applied for the detection of targeted DNA during real-time PCR analysis (Kesmen et al. 2007). They were widely defined as "specific" or "non-specific" for the amplified sequence. In the present study, a TaqMan probe was used, being a kind of "specific" detection chemistry, in which a short sequence of oligonucleotides is specified and labelled with two fluorescent dyes which specifically attach to the targeted DNA and release a fluorescence signal with simultaneous DNA amplification (Higgins et al. 1992). The sequence of nucleotides in the TaqMan probe is compatible with the sequence of the targeted DNA in the genome of identified bacteria which makes it possible to detect this bacteria without the need for any further confirmatory assays (Monteil-Sosa et al. 2000; Hird et al. 2005; Rodriguez et al. 2005).

To guarantee the successfulness and sensitivity of the designed real-time PCR assay for the detection of a very small number of cells of Yersinia enterocolitica ( $Y$. enterocolitica) in raw meat, a 20 h-long pre-enrichment stage in a nutritious non-selective medium was necessary for the multiplication of Yersinia cells to a number high enough to be detected by the PCR analysis (Saez et al. 2004; Tanabe et al. 2007; Martín et al. 2009). There have been some successful attempts to shorten this long pre-enrichment step to $8 \mathrm{~h}$ to detect and quantitatively specify the number of pathogenic cells in pig carcasses. However, this step was still too time-consuming. For the purpose of the present study, a time-effective and highly specific TaqMan probe-based real-time polymerase chain reaction protocol was designed involving a brief pre-enrichment step lasting for $4 \mathrm{~h}$ and enabling to detect a very low number of pathogenic Yersinia cells in raw pork meat (Rodríguez et al. 2003; Sawyer et al. 2003; Walker et al. 2003).

\section{Materials and Methods}

Bacterial strains and growth conditions

A mixture of 12 Yersinia enterocolitica strains (collection of Ghent University, Belgium) was used for the purpose of this study. Each strain culture was prepared by taking a single colony which was grown on tryptone soya agar (TSA) (Oxoid, UK) and placing it into $10 \mathrm{ml}$ of tryptone soya broth (TSB) (Oxoid, UK). It was incubated at $30{ }^{\circ} \mathrm{C}$ for 16-24 h. An overnight culture was carried out individually for each strain, then it was mixed equally together, and serially diluted to different cell concentrations in TSB. There were also some other microorganisms which were prepared in the same way and cultured in the conditions specified above. The only difference was that they were incubated at $37^{\circ} \mathrm{C}$ for $16-24 \mathrm{~h}$. These microorganisms involved Escherichia coli ATCC 25922, Shigella flexneri ATCC 12022, Enterobacter cloacae ATCC 13047, Klebsiella pneumoniae ATCC 35657, and Pseudomonas aeruginosa ATCC 27853.

Evaluation of a viable number of cells of Yersinia enterocolitica directly from naturally contaminated raw pork meat

Viable cells of $Y$. enterocolitica strains in raw pork meat were evaluated by the standard plate count technique. Samples of raw pork meat were taken aseptically, placed into sterile plastic bags and stored under chilled conditions for the purpose of our study. The samples of meat were checked for the presence of pathogenic $Y$. enterocolitica by direct plating and different enrichment protocols according to the International Organization for Standardization (ISO) method. Meat samples were aseptically cut into small pieces, and $10 \mathrm{~g}$ of meat were put into a sterile stomacher bag. Samples were homogenized with $90 \mathrm{ml}$ of $0.1 \%$ peptone water (Oxoid, UK) for $2 \mathrm{~min}$ in a stomacher (Colworth Stomacher 400, Seward Ltd, London, UK). Then, $0.1 \mathrm{ml}$ of such homogenate was placed on cefsulodin-irgasan-novobiocin (CIN) agar plates (Yersinia Selective Agar Base and Yersinia Selective Supplement, Oxoid, UK) by a spiral plate machine (Eddie Jet, IUL Instruments, Barcelona, Spain). Then, the CIN agar plates were incubated at $30^{\circ} \mathrm{C}$ for $24 \mathrm{~h}$ and investigated for characteristic Yersinia colonies using a stereo microscope with Henry illumination (Olympus, Germany).

Suspected colonies were taken by a sterile loop and incubated in trypton soy broth (PCA, Oxoid, UK) at $30^{\circ} \mathrm{C}$ for $4 \mathrm{~h}$ and for $20 \mathrm{~h}$. Then the culture grown in trypton soy broth was taken for the real-time PCR analysis. Suspected colonies of $Y$. enterocolitica were also inoculated on Plate Count Agar at $30^{\circ} \mathrm{C}$ for $24 \mathrm{~h}$ and then taken for biochemical testing.

Pre-enrichment step

Twenty-five mg of raw pork meat samples free from pathogenic cells of $Y$. enterocolitica were inoculated with a mixture of $12 Y$. enterocolitica strains listed in Table 1 . The inoculation level was $1 \mathrm{ml}$ of bacterial mixture 
containing $10^{2} \mathrm{cfu}$. The samples were inoculated in $225 \mathrm{ml}$ of pre-warmed TSB and buffered peptone water (BPW) (Oxoid, UK), incubated at $30^{\circ} \mathrm{C}$ for $4 \mathrm{~h}$ with simultaneous shaking at $200 \mathrm{rpm}$. Samples were examined in duplicate. Ten $\mathrm{ml}$ of pre-enriched culture were subjected to DNA extraction. Raw pork samples which were used for inoculation were previously tested negative with a PCR method.

Table 1. List of Yersinia enterocolitica strains used in the study.

\begin{tabular}{|c|c|c|c|c|c|}
\hline Species & Original strain no. & Biotype & Serotype & $\begin{array}{c}\text { Virulence } \\
\text { gene/virulence } \\
\text { plasmid }\end{array}$ & Collection \\
\hline Y. enterocolitica & YE1 & 4 & $0: 3$ & ail $^{1}$, ystA $^{2}$ & Ghent University, Belgium \\
\hline Y. enterocolitica & YE3 & 4 & $0: 3$ & ail, ystA & Ghent University, Belgium \\
\hline Y. enterocolitica & YE5 & 4 & $0: 3$ & ail, ystA & Ghent University, Belgium \\
\hline Y. enterocolitica & YE7 & 4 & $0: 3$ & ail, ystA & Ghent University, Belgium \\
\hline Y. enterocolitica & YE165 & 3 & $0: 3$ & ail, ystA & Ghent University, Belgium \\
\hline Y. enterocolitica & KNG22703 & 2 & $0: 9$ & pYV ${ }^{3}$ & Ghent University, Belgium \\
\hline Y. enterocolitica & $2516-87$ & 2 & O:9 & pYV & Ghent University, Belgium \\
\hline Y. enterocolitica & 8081 & $1 \mathrm{~B}$ & $\mathrm{O}: 8$ & ail, pYV & Ghent University, Belgium \\
\hline Y. enterocolitica & WA & $1 \mathrm{~B}$ & $0: 8$ & pYV & Ghent University, Belgium \\
\hline Y. enterocolitica & W22703 & 2 & O:9 & pYV & Ghent University, Belgium \\
\hline $\begin{array}{l}\text { Y. enterocolitica } \\
\text { subsp. palearctica }\end{array}$ & $105.5 \mathrm{R}(\mathrm{r})$ & 3 & O:9 & pYV & Ghent University, Belgium \\
\hline $\begin{array}{l}\text { Y. enterocolitica } \\
\text { subsp. palearctica }\end{array}$ & Y11 & 4 & $0: 3$ & ail, ystA & Ghent University, Belgium \\
\hline
\end{tabular}

ail $^{1}$ (it encodes the attachment invasion locus protein), ystA ${ }^{2}$ (it encodes the production of enterotoxins Yst (Yersinia stable toxins)) - these target genes are found in the chromosome, they are virulence factors found in pathogenic Y. enterocolotica strains; $\mathrm{pYV}^{3}$ (Yersinia virulence plasmid) - it is the virulence plasmid which encodes a type III secretion system (ysc and lcr genes) essential for delivery of additional plasmid-borne anti-host factors collectively referred to as Yops (Yersinia outer proteins). It is a virulence factor found in pathogenic Y. enterocolotica strains.

\section{Biochemical testing}

Urea Agar according to Christensen

Bacterial material from the PCA was taken with a loop and incubated on Urea Agar according to Christensen (Oxoid, UK) at $30^{\circ} \mathrm{C}$ for $24 \mathrm{~h}$. Pink-violet or red-pink colour indicated a positive urease reaction. An orangeyellow colour indicated a negative urease reaction.

\section{Kligler Iron Agar}

Bacterial material from the PCA was taken with a loop, put on the slant surface of Kligler Iron Agar (Oxoid, $\mathrm{UK}$ ) and incubated at $30^{\circ} \mathrm{C}$ for $24 \mathrm{~h}$. Yersinia enterocolitica is glucose positive and lactose negative, and does not form $\mathrm{H}_{2} \mathrm{~S}$ or gas.

\section{Bile Esculine Agar}

Bacterial material from the PCA was taken with a loop, put on the surface of Petri dishes of Bile Esculine Agar (Oxoid, UK) and incubated at $30{ }^{\circ} \mathrm{C}$ for $24 \mathrm{~h}$. A black halo around the colonies indicated a positive reaction. Pathogenic $Y$. enterocolitica were negative.

\section{DNA extraction}

A $10-\mathrm{ml}$ portion of $4 \mathrm{~h}$-bacterial culture in TSB and BPW was centrifuged at $11.700 \times \mathrm{g}$ for 10 min, washed in $5 \mathrm{ml}$ of $0.1 \times \mathrm{SSC}(1 \times \mathrm{SSC}$ is $0.15 \mathrm{M} \mathrm{NaCl}, 0.015 \mathrm{M}$ sodium citrate), suspended in $1 \mathrm{ml}$ of $0.01 \mathrm{M}$ sodium phosphate buffer in $20 \%$ sucrose $(\mathrm{pH} 7.0)$ with lysozyme $(2.5 \mathrm{mg} / \mathrm{ml})$ and incubated $45 \mathrm{~min}$ at $37{ }^{\circ} \mathrm{C}$. A $9-\mathrm{ml}$ portion of lysis buffer $(10 \mathrm{mM}$ Tris-hydro-chloride [pH 8.0], $1 \mathrm{mM}$ ethylenediaminetetraacetic acid (EDTA), $500 \mu \mathrm{g}$ of pronase B per $\mathrm{ml}, 1 \%$ sodium dodecyl sulphate) were then added. After additional $30 \mathrm{~min}$ at $37^{\circ} \mathrm{C}$, the samples were deproteinized by extraction with phenol and chloroform, and nucleic acids were precipitated with ethanol. The samples were suspended in $10 \mathrm{mM}$ Tris-hydrochloride (pH 8.0), $1 \mathrm{mM}$ EDTA and stored at $4{ }^{\circ} \mathrm{C}$. The concentration of DNA $(\mathrm{ng} / \mu \mathrm{l})$ was measured by the spectrophotometer (Evolution 220, Thermoscientific, USA). 
The mass (M) of 1 genomic molecule was counted on the base of the equation $\mathrm{M}=\mathrm{n} \times\left(1.01 \times 10^{-21} \mathrm{~g} \cdot \mathrm{bp} \mathrm{p}^{-1}\right)$; for Yersinia $4.616 \times 10^{6} \mathrm{bp}$. The quantified DNA (number of genomic copies/ $\mu \mathrm{l}$ ) was serially diluted in water and underwent the real-time PCR according to the conditions specified below.

\section{Real-time PCR reactions}

DNA extracted from $Y$. enterocolitica was subjected to a TaqMan probe-based real-time PCR assay targeting a DNA sequence within the CH49_3099 locus gene specific for pathogenic strains of $Y$. enterocolitica. The assay included a forward primer, a reverse primer, a target TaqMan probe (FAM-MGB-NFQ labelled), the internal amplification control (IAC) template, and IAC probe.

The primer/probe set targeting locus_tag CH49_3099 gene was designed on the base of 50-nucleotide sequence GACGATACCTTGGTATAGCAATCTATTTAGCACTGATGTGTCGGTTCCGG specific for $Y$. enterocolitica species. The sequence of the gene was provided by GenBank (www.ncbi.nlm.nih.gov/Genbank/; Accession Number CP009846.1). Sequences unique to $Y$. enterocolitica were compared with those of closely related strains (Table 2). The primer/probe set was designed using Primer Express Software v3.0 (Applied Biosystems, Foster City, CA, USA). The set was validated using NCBI BLAST (Basic Local Alignment Search Tool: www.ncbi.nlm. nih.gov/blast/). The sequences were as follows: forward primer 5'-GACGATACCTTGGTATAGC-3'; reverse primer 5'- ATAGCTGATGACTTTAT-3'; probe 5'-FAM- CCGGAACCGACACATCAGTGCTAAATAGAT-3'MGB-NFQ. The amplicon size was 66 bases. The oligonucleotides were synthesised and purchased from Eurofins Genomics (Germany).

The reaction total volume was $20 \mu \mathrm{l}$. Real-time PCR analysis was performed using the thermocycler of Stratagene Mx3005P (Agilent Technologies, USA). The PCR mixture contained $5 \mu$ l DNA template, $12.5 \mu 1$ of TaqMan Universal Master Mix (Syngen Biotech, United Kingdom), $600 \mathrm{nM}$ of primers R and F respectively, and $200 \mathrm{nM}$ of FAM-MGB-NFQ labelled probe. A non-template control (NTC) contained $5 \mu 1$ of water instead of DNA and was included in each run. The real-time PCR cycling parameters were the following: 1 cycle of initial denaturation of DNA at $95{ }^{\circ} \mathrm{C}$ for 10 min followed by 40 cycles of amplification with denaturation at $95{ }^{\circ} \mathrm{C}$ for $15 \mathrm{~s}$, and annealing and extension at $60{ }^{\circ} \mathrm{C}$ for $1 \mathrm{~min}$. The real-time PCR reaction and amplification step were carried out using a DNA amplification curves which were the subject of analysis. The calculation of the threshold cycle $\left(C_{T}\right)$ value was carried out using Stratagene Mx3005P software version 2.1 (Agilent Technologies, USA). The $C_{T}$ value was described as the real-time PCR cycle, at which the generated fluorescence increased exponentially and exceeded its background level.

\section{Statistical analysis}

Each experiment was repeated at least three times and data were analysed using analysis of variance (ANOVA) and Duncan multiple range test $(P<0.05)$.

\section{Results}

Sensitivity of the TaqMan probe-based real-time PCR protocol for the detection of Yersinia enterocolitica species in raw pork meat without pre-enrichment

A detection limit of the TaqMan probe-based, real-time PCR protocol which made it possible to directly assess different concentrations in the range from 1 to $10^{8} \mathrm{cfu} \cdot 25 \mathrm{mg}^{-1}$

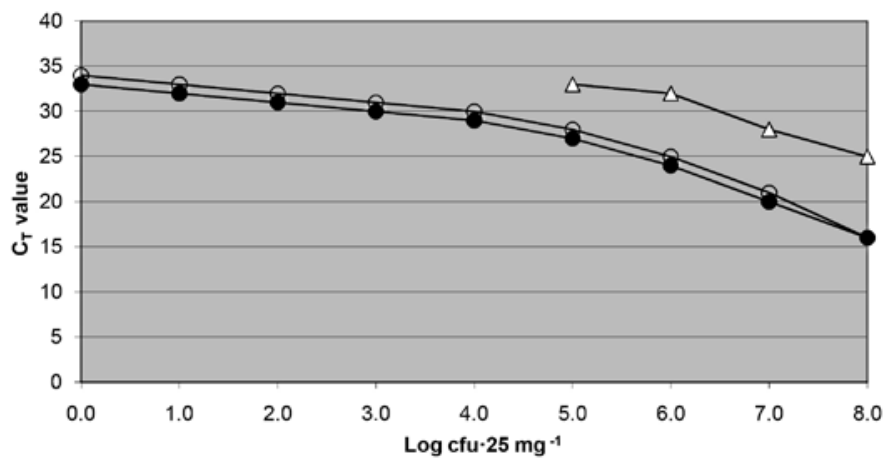

Fig. 1. Detection of various concentrations of Yersinia enterocolitica strains in $25 \mathrm{mg}$ of raw pork meat samples by the real-time PCR without pre-enrichment $\left.{ }^{\Delta}\right)$ and after brief pre-enrichment for $4 \mathrm{~h}$ in BPW (०), and after brief preenrichment for $4 \mathrm{~h}$ in $\operatorname{TSB}(\bullet)$. $C_{T}$ values are means of at least 3 separate determinations. of $Y$. enterocolitica in raw pork meat without the pre-enrichment step was the subject of investigation. It was observed that higher $C_{T}$ values were found when there was a decrease in the total number of viable cells of $Y$. enterocolitica. Such phenomenon was attributed to the decrease in the amount of DNA coming from cells (Fig. 1). The real-time PCR analysis enabled to detect viable cells 
at a level of $10^{5}-10^{8} \mathrm{cfu} \cdot 25 \mathrm{mg}^{-1}$ of $Y$. enterocolitica in raw pork meat without the preenrichment step, and the $C_{T}$ values were in a range from 33 to 25 (Fig. 1). It was not possible to detect viable cells of $Y$. enterocolitica in a number lower than $10^{5} \mathrm{cfu} \cdot 25 \mathrm{mg}^{-1}$. So the detection limit of the protocol designed for the need of this study was a value of $10^{5} \mathrm{cfu} \cdot 25 \mathrm{mg}^{-1}$ for viable cells.

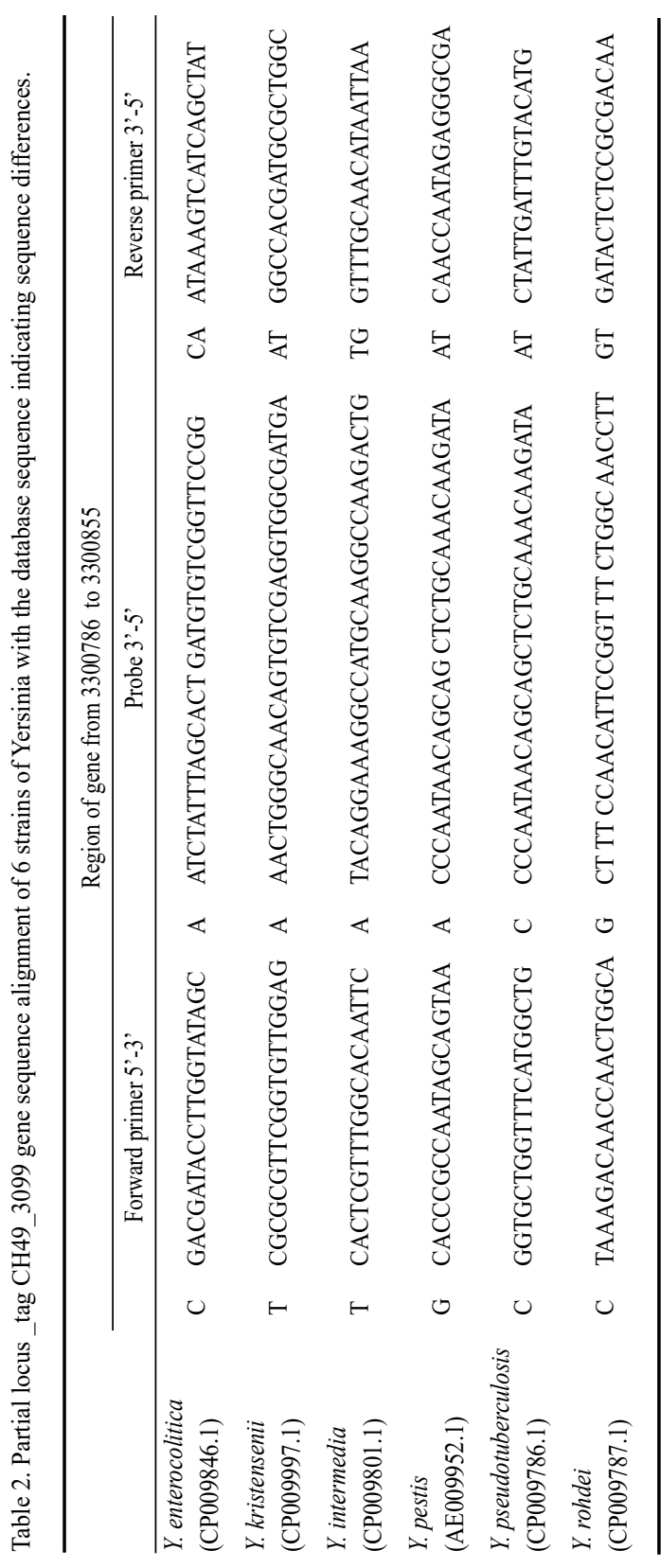

Application of the $4 \mathrm{~h}$ preenrichment step in BPW and TSB In order to evaluate the sensitivity of the TaqMan probe-based real-time PCR protocol towards the assessment of the number of viable cells of Yersinia enterocolitica in raw pork meat, a brief pre-enrichment step lasting for $4 \mathrm{~h}$ before real-time PCR analysis was applied. Its aim was to establish the detection limit of the protocol which meant the lowest number of detectable viable cells. The pre-enrichment steps involved in this protocol were carried out in two culture media, TSB and BPW. They were applied with the conjunction of the real-time PCR to assess the number of viable cells of $Y$. enterocolitica in the range of $1-10^{8} \mathrm{cfu} \cdot 25 \mathrm{mg}^{-1}$. The involvement of pre-enrichment steps in the realtime PCR protocol enabled to detect a number of pathogenic cells in the range from $1 \mathrm{cfu} \cdot 25 \mathrm{mg}^{-1}$ which constitutes the detection limit (Fig. 1). It was found that slightly higher $C_{T}$ values were observed in the case of application of the 4-h pre-enrichment step in BPW in comparison to the 4-h pre-enrichment in TSB. However, the differences were very small $(P<0.05)$. It means that both media are suitable to be used in combination with the real-time PCR analysis. The present study proves that both culture media can be successfully used as a preenrichment step to multiply the number of $Y$. enterocolitica cells to be detected during the real-time PCR analysis.

\section{Discussion}

Yersinia species very often naturally contaminate meat and meat products. As they are often 
accompanied by other members of the Enterobacteriaceae, the designed 4-h preenrichment/real-time PCR protocol was checked for the ability to detect different concentrations of $Y$. enterocolitica in mixed cultures in raw pork meat (López-Andreo et al. 2006; Laube et al. 2007). The accompanied bacteria were represented by E. coli, S. flexneri, E. cloacae, K. pneumoniae, and P. aeruginosa. To check the competition among these species, mixed cultures were applied to deliver a large number of cells at a level of $10^{7}-10^{8} \mathrm{cfu} \cdot 25 \mathrm{mg}^{-1}$. The accompanied bacteria did not influence the method sensitivity and $Y$. enterocolitica was detectable at a level even as low as $1 \mathrm{cfu} \cdot 25 \mathrm{mg}^{-1}$ of raw pork meat with the application of either TSB or BPW as a pre-enrichment media.

The results of the present investigation prove that the $4 \mathrm{~h}$ pre-enrichment step either in TSB or BPW in the combination with the real-time PCR method is a very time-effective and highly specific TaqMan probe-based real-time polymerase chain reaction protocol for the detection of $Y$. enterocolitica in raw pork meat (Sawyer et al. 2003). The analysis lasts for approximately $5.5 \mathrm{~h}$ in comparison to at least 3 days when the traditional culturebased method is applied. The shortening of the pre-enrichment time to $4 \mathrm{~h}$ was crucial and contributed to making the analysis more rapid in comparison with cultivating the strains overnight. Application of the 4-h pre-enrichment step in the present research enables to provide the results within the same working day. Moreover, the detection limit for the designed 4-h pre-enrichment/real-time PCR protocol amounted to $1 \mathrm{cfu} \cdot 25 \mathrm{mg}^{-1}$, which proved a very high sensitivity of the probe/primers set for the identification of Y. enterocolitica species in raw pork meat (Jonker et al. 2008; Kesmen et al. 2009; Koppel et al. 2011). The very low detection limit of Yersinia strains can be also explained by the fact that in meat there is a very high availability of nutrients, and lack of growth inhibitors in pre-enriched meat samples which might encourage the multiplication of Yersinia to achieve the levels that are detectable within only $4 \mathrm{~h}$ (Kesmen et al. 2007). Moreover, the designed protocol was found to be successful in the detection of as few as $1 \mathrm{cfu} \cdot 25 \mathrm{mg}^{-1}$ of Yersinia in meat samples not only thanks to the specific sequences of nucleotides in the set of probe/primers but also thanks to the application of the preenrichment step in BPW and TSB pre-warmed to $30{ }^{\circ} \mathrm{C}$, and shaking cultures during the pre-enrichment time.

In conclusion, the results of the study proved that the designed TaqMan probe-based real-time polymerase chain reaction protocol for the identification of $Y$. enterocolitica in raw pork meat is very time-effective and highly specific because within approximately $5.5 \mathrm{~h}$ it is able to detect as few as $1 \mathrm{cfu} \cdot 25 \mathrm{mg}^{-1}$ of $Y$. enterocolitica in raw pork meat. It enables the detection of Yersinia in a quantitative form in meat and meat products. It constitutes a very useful tool in the assessment of microbial contamination and in the hazard analysis critical control points plans.

\section{Acknowledgements}

This work was supported by the funds granted by Ministry of Science and Higher Education of Poland within Project No BDS-15/ITŻiG/10/2013.

\section{References}

Dooley JJ, Paine KE, Garrett SD, Brown HM 2004: Detection of meat species using TaqMan real-time PCR assays. Meat Sci 68: 431-438

Girish PS, Anjaneyulu ASR, Viswas KN, Santhosh FH, Bhilegaonkar KN, Agarwal RK, Kondaiah N, Nagappa K 2007: Polymerase chain reaction-restriction fragment length polymorphism of mitochondrial 12S rRNA gene: a simple method for identification of poultry meat species. Vet Res Comm 31: 447-455

Heptinstall J, Rapley R 2002: Spectrophotometric analysis of nucleic acids. In Rapley R (editor): The nucleic acid protocols handbook, pp 57-60, Totowa, N.J.: Humana Press

Herman L 1992: Determination of animal origin of raw food by species-species PCR. J Dairy Res 68: 429-436

Higgins DG, Bleasby AJ, Fuchs R 1992: CLUSTAL W: improved software for multiple sequence alignment. Comp Appl Biosci 8: 4420-4449 
Hird H, Chisholm J, Brown J 2005: The detection of commercial duck species in food using a single probemultiple species-specific primer real-time PCR assay. Eur Food Res Technol 221: 559-563

Jonker KM, Tilburg JJHC, HaGele GH, De Boer E 2008: Species identification in meat products using real-time PCR. Food Add Contam 25: 527-533

Kesmen Z, Sahin F, Yetim H 2007: PCR assay for the identification of animal species in cooked sausages. Meat Sci 77: 649-653

Kesmen Z, Gulluce A, Sahin F, Yetim H 2009: Identification of meat species by TaqMan-based real-time PCR assay. Meat Sci 82: 444-449

Kocher TD, Thomas WK, Meyer A, Edwards SV, Päabo S, Villablanca FX, Wilson AC 1989: Dynamics of mitochondrial DNA evolution in animals: amplification and sequencing with conserved primers. Proc Nat Acad Sci USA 86: 6196-6200

Koppel R, Ruf J, Rentsch J 2011: Multiplex real-time PCR for the detection and quantification of DNA from beef, pork, horse and sheep. Eur Food Res Technol 232: 151-155

Laube I, Zagon J, Spiegelberg A, Butschke A, Kroh LW, Broll H 2007: Development and design of a 'ready-touse' reaction plate for a PCR-based simultaneous detection of animal species used in foods. Int J Food Sci Technol 42: 9-17

López-Andreo M, Garrido-Pertierra A, Puyet A 2006: Evaluation of postpolymerase chain reaction melting temperature analysis for meat species identification in mixed DNA samples. J Agric Food Chem 54: 7973-7978

Mane BG, Mendiratta SK, Tiwari AK 2009: Polymerase chain reaction assay for identification of chicken in meat and meat products. Food Chem 116: $806-810$

Martín I, García T, Fajardo V, Rojas M, Pegels N, Hernández PE, Martín IG 2009: SYBR-Green real-time PCR approach for the detection and quantification of pig DNA in feedstuffs. Meat Sci 82: 252-259

Monteil-Sosa JF, Ruiz-Pesini E, Montoya J, Roncales P, López-Pérez MJ, Pérez-Martos A 2000: Direct and highly species-specific detection of pork meat and fat in meat products by PCR amplification of mitochondrial DNA. J Agric Food Chem 48: 2829-2832

Rodríguez MA, García T, González I, Asensio L, Mayoral B, López-Calleja I, Hernández PE, Martín R 2003: Identification of goose, mule duck, chicken, turkey, and swine in foie gras by species-specific polymerase chain reaction. J Agric Food Chem 51: 1524-1529

Rodriguez MA, García T, González I, Hernández PE, Martín R 2005: TaqMan real-time PCR for detection and quantitation of pork in meat mixtures. Meat Sci 70: 113-120

Saez R, Sanz Y, Toldrá F 2004: PCR-based fingerprinting techniques for rapid detection of animal species in meat products. Meat Sci 66: 659-665

Sawyer J, Wood C, Shanahan D, Gout S, McDowell D 2003: Real-time PCR for quantitative meat species testing. Food Cont 14: 579-583

Tanabe S, Hase M, Yano T, Sato M, Fujimura T, Akiyama H 2007. Real-time quantitative PCR detection method for pork, chicken, beef, mutton, and horse flesh in foods. Biosci Biotechnol Biochem 71: 3131-3135

Walker JA, Hughes DA, Anders BA, Shewale J, Sinha SK, Batzer MA 2003: Quantitative intra-short interspersed element PCR for species-specific DNA identification. Anal Biochem 316: 259-269 